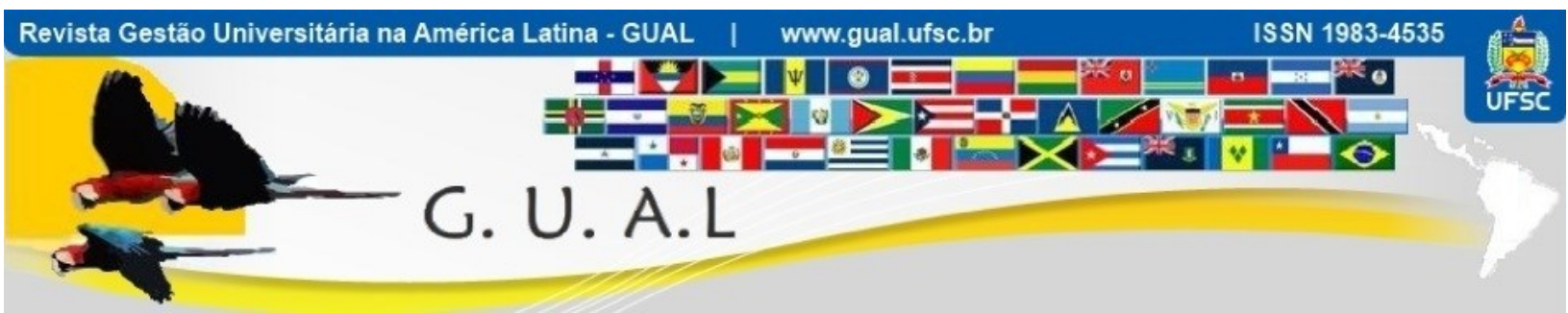

DOI: http://dx.doi.org/10.5007/1983-4535.2020v13n1p205

\title{
PERCEPÇÕES E AÇÕES DE PROFESSORES SOBRE PRÁTICAS DESONESTAS DE DISCENTES
}

\section{TEACHERS' PERCEPTIONS AND ACTIONS ON STUDENTS' DISHONEST PRACTICES}

\author{
Ananda Silva Singh, Mestre \\ https://orcid.org/0000-0003-4919-5649 \\ a.singh@uol.com.br \\ Universidade Federal do Paraná | Programa de Pós Graduação em Administração \\ Curitiba | Paraná | Brasil \\ Ana Beatriz Murillo Oviedo, Mestre \\ https://orcid.org/0000-0003-2819-3935 \\ ana.murillo.oviedo@una.ac.cr \\ Universidad Nacional de Costa Rica | Departamento de Administração \\ San José | San Pedro | Costa Rica \\ Leonardo Rodrigues Pires, Mestre \\ https://orcid.org/0000-0001-9727-6764 \\ leorpires@yahoo.com.br \\ Universidade Federal de Uberlândia | Programa de Pós-graduação em Administração \\ Uberlândia | Minas Gerais | Brasil \\ Valdir Machado Valadão Junior, Doutor \\ https://orcid.org/0000-0001-7930-8056 \\ valdirjr@ufu.br \\ Universidade Federal de Uberlândia | Programa de Pós-graduação em Administração \\ Uberlândia | Minas Gerais | Brasil \\ Eduardo De-Carli, Doutor \\ https://orcid.org/0000-0001-5853-9488 \\ eduardodecarli@ufpr.br \\ Universidade Federal do Paraná | Programa de Pós Graduação em Administração \\ Curitiba | Paraná | Brasil \\ Andréa Paula Segatto, Doutora \\ https://orcid.org/0000-0002-8903-9256 \\ andreapsegatto@gmail.com \\ Universidade Federal do Paraná | Programa de Pós Graduação em Administração \\ Curitiba | Paraná | Brasil
}

Recebido em 03/março/2019

Aprovado em 25/junho/2019

Publicado em 02/janeiro/2020

Sistema de Avaliação: Double Blind Review

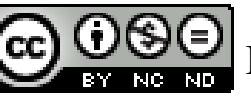

Esta obra está sob uma Licença Creative Commons Atribuição-Uso. 


\title{
RESUMO
}

Evitar a ocorrência de práticas desonestas no ensino superior consiste em parte do trabalho do professor, trazendo como desafio ao professor a inclusão de ações e metodologias para diminuir a ocorrência de tais práticas, no planejamento de suas atividades. É neste cenário que esta pesquisa se insere, visto que busca compreender a ocorrência de práticas desonestas, a partir da percepção de professores dos cursos de Administração de duas universidades federais brasileiras. O método para procedimento foi o estudo de caso, qualitativo, descritivo e cuja fonte de dados consiste de entrevistas estruturadas. Os dados são analisados pela análise de conteúdo e os resultados evidenciam que práticas desonestas são as que primam pela obtenção de vantagens pessoais em oposição à coletividade, ocorrendo em forma de plágio e cola. Essas práticas são decorrentes de falta de punição e de falta de esforço dos alunos, sendo que o professor pode mitigar suas ocorrências ao utilizar diferentes metodologias de ensino e, principalmente, através da conscientização dos discentes acerca das consequências de práticas desonestas.

Palavras-chave: Práticas Desonestas. Ensino Superior. Administração.

\begin{abstract}
To avoid the occurrence of dishonest practices in higher education has become part of the teachers' work, becoming a challenge they have to face in order to include in the planning of their activities, actions and methodologies aiming to reduce such unwanted practices. It is in this scenario that this research lies, since it seeks to understand the occurrence of dishonest practices, from the perception of teachers of Administration courses in two public universities. A qualitative, descriptive case study was held, collecting data through structured interviews. Data were analyzed through the content analysis technique and the results showed that dishonest practices are conspicuous by obtaining personal advantage, they occur in the form of plagiarism and in the form of copies of others' work. They are motivated by lack of punishment and lack of effort from students, and by using different methodologies and contributing to better develop the students consciousness regarding dishonest behavior, such practices can be mitigated by teachers.
\end{abstract}

Keywords: Dishonest Practices. Higher Education. Business Administration. 


\section{INTRODUÇÃO}

As mudanças na sociedade, nas visões de mundo e nas funções sociais da educação têm trazido para a profíssão docente desafios que vão além daqueles relacionados ao planejamento e à execução de atividades pedagógicas. Dentre eles estão a priorização de resultados quantitativos em detrimento dos qualitativos, acarretando na eliminação da reflexão crítica dos alunos, nas salas de aula; regras, avaliações, rituais e cobranças do sistema sobre os professores, colocando a qualidade e a liberdade acadêmica em xeque (FREITAS, 2007; ALCADIPANI, 2011, FROTA; TEODÓSIO, 2012); aumento do tamanho das turmas, da carga de trabalho e de pressões, provocando esgotamento emocional e despersonalização, com consequente perda de autonomia e motivação pela docência (FROTA; TEODÓSIO, 2012); o desinteresse por parte dos estudantes (AKTOUF, 2005; CRUZ, 2009); além da quantidade de atividades que perpassam as de sala de aula, como atividades administrativas, pesquisa e extensão (MATOS, 2019). Tais desafios acabam comprometendo o estreitamento das relações discente-docente em sala de aula, bem como o processo de aprendizagem.

Somado a essas condições dificultadoras da atividade docente, é imposta também aos professores a tarefa de combater comportamentos de desonestidade acadêmica por parte dos alunos. Zahra, Priem e Rasheed (2005) argumentam que para os professores conseguirem um comportamento mais ético por parte de seus alunos, eles precisam compreender os motivos que os levam à prática de fraudes acadêmicas.

Nessa perspectiva, Eastman, Iyer e Reisenwitz (2008) afirmam que estudos têm demonstrado a existência de diversas razões que explicam o comportamento antiético dos alunos, como: (i) desejo de ganhar algo, como a obtenção de maior grau de instrução, (ii) falta de motivação, mesmo tendo disponibilidade de tempo, muitas vezes os alunos não estudam e consideram irrelevante o trabalho solicitado pelos docentes, (iii) situações que 'justificam' o comportamento antiético, como a ausência de tempo ou de material para realização do trabalho acadêmico, ou a concepção de que o professor tem pouco conhecimento ou é desinteressado, ou ainda a pressão dos colegas para que o discente se comporte de determinadas maneiras, e (iv) percepção de que o comportamento antiético tem um baixo impacto negativo sobre si mesmo e sobre o próximo como, por exemplo, a percepção de que existe um baixo risco de ser descoberto, ou porque é a 'forma como todo mundo age', ou que normalmente saem impunes de situações nas quais se comportam inadequadamente. 
Diante desses aspectos, mostra-se pertinente que professores avaliem, melhorem e desenvolvam técnicas para prever e prevenir comportamentos antiéticos. Neste sentido, estudos relacionados à docência de ensino superior têm contemplado a pesquisa sobre práticas desonestas de alunos, como por exemplo a cola ou o plágio, buscando identificar quais são principais práticas desonestas realizadas por discentes de instituições de ensino superior e como se dá a percepção dos estudantes a respeito das mesmas.

Em se tratando de alunos do curso da área de negócios, a preocupação quanto a atitudes antiéticas tem levantado interesse de maneira especial entre os pesquisadores, visto que existe uma preocupação de que tais atitudes possam transpassar ao espaço laboral (SOUSA et al., 2016; SILVA JUNIOR et al., 2017). Complementarmente, Borges, Medeiros e Casado (2011) ressaltam que muitos autores têm questionado como estão sendo formados os alunos dos cursos das áreas de negócios, os quais desempenharão importantes funções nas organizações públicas e privadas.

Diante disto e também do fato que estudos como o de Miller et al. (2011) mostraram a inexistência de relação entre as características dos discentes com sua orientação para a realização de práticas desonestas, neste estudo optou-se por utilizar professores como participantes da pesquisa, para compreender a ocorrência de práticas desonestas no ensino superior.

Frente a este contexto, o presente estudo tem como objetivo analisar, a partir das percepções dos professores dos cursos de Administração de Universidades públicas dos Estados de Minas Gerais e do Paraná, como ocorrem as práticas desonestas dos estudantes dessas Instituições de Ensino Superior (IES). Especificamente, buscou-se analisar (i) o que professores entendem por práticas desonestas e situações em que tais práticas ocorrem, (ii) as motivações e elementos que levam estudantes a realizar tais ações, (iii) técnicas e estratégias utilizadas pelos docentes para mitigar as práticas desonestas dos discentes e, por fim, (iv) as técnicas utilizadas pelos docentes para punir tais práticas.

\section{REFERENCIAL TEÓRICO}

\subsection{PRÁTICAS DESONESTAS NAS INSTITUIÇÕES DE ENSINO SUPERIOR}

A definição da prática desonesta é, na maioria das vezes, relacionada aos atos que faltam à integridade acadêmica estabelecida em regulamentos. Pode ser também relacionada a atos que transgridem a propriedade e a produção intelectual. Baseado no Código de Integridade Acadêmica da Universidade de Cornell, Shikida (2016) expõe como práticas 
desonestas: (i) os trabalhos apresentados pelos estudantes que não possuem originalidade, sendo copiados ou plagiados; (ii) a participação de estudantes em práticas fraudulentas para obterem aprovação em disciplinas, e (iii) quando os estudantes não respeitam o código de integridade acadêmica da faculdade.

Em pesquisa feita por McCabe (2005), realizada com professores e alunos de faculdades dos Estados Unidos e do Canadá, foram analisadas outras práticas desonestas diferentes do plágio, que foram classificadas segundo o método de avaliação que foi fraudado, conforme descrito no quadro 1.

Quadro 1 Práticas desonestas na academia

\begin{tabular}{c|l}
\hline $\begin{array}{c}\text { AVALIAÇÃO } \\
\text { FRAUDADA }\end{array}$ & \multicolumn{1}{c}{ PRÁTICAS DESONESTAS } \\
\hline \multirow{2}{*}{ Provas e exames } & $\begin{array}{l}\text { - Colar respostas de outro colega com ou sem o consentimento do outro. } \\
\text { - Dar resposta às perguntas de colegas durante a prova. } \\
\text { - Usar notas durante as provas sem a permissão do professor. } \\
\text { - Antes de fazer a prova, perguntar sobre ela para quem já a fez. } \\
\text { - Criar justificativas para atrasar uma prova ou a entrega de um trabalho com o fim } \\
\text { de ter mais tempo para estudar ou para fazê-lo. } \\
\text { - Usar sem permissão alguma tecnologia para obter informação durante uma } \\
\text { prova. }\end{array}$ \\
\hline Trabalhos escritos & $\begin{array}{l}\text { - Fazer trabalhos individuais em grupo. } \\
\text { - Copiar ou parafrasear textos impressos ou digitais sem citação. } \\
\text { - Receriação de bibliografia falsa. } \\
\text { - Entregar um trabalho feito por outra pessoa. } \\
\text { - Entregar um trabalho copiado do trabalho de outro colega. } \\
\text { - Copiar partes do texto sem citação. }\end{array}$ \\
\hline Outros tipos de \\
trabalhos
\end{tabular}

Fonte: McCABE (2005).

Complementarmente ao exposto no quadro 1, Orosz et al. (2015) apontam outros comportamentos que também caracterizam como desonestos, como por exemplo a utilização de folhas para colar; o ato de colar propriamente dito; plágio; apresentação de um mesmo trabalho para várias disciplinas; a utilização de equipamento eletrônico sem autorização; tomar o lugar de outra pessoa em provas ou apresentar trabalhos de outros como se fossem próprios.

Neste contexto, elemento que merece destaque por se apresentar relevante nos estudos de práticas desonestas no ensino superior se refere às motivações para a realização de tais práticas, ou seja, o que leva os discentes a terem comportamentos contrários àqueles condizentes com a integridade acadêmica. 


\subsection{MOTIVAÇÕES DE DISCENTES PARA REALIZAÇÃO DE PRÁTICAS DESONESTAS}

A prática de ações desonestas na academia, como por exemplo a cola ou o plágio, podem implicar no (i) comprometimento da formação dos futuros profissionais e do serviço que a Universidade presta à sociedade e (ii) na padronização da ideia de que a fraude é uma forma de solução dos problemas da vida no âmbito pessoal, acadêmico e empresarial. Uma vez que tais situações são indesejadas, mostra-se pertinente compreender o que leva os estudantes a agir de tal forma, ou seja, as motivações que os induzem a comportamentos antiéticos (LAMBERT; HOGAN; BARTON, 2003).

As percepções e práticas realizadas pelos estudantes têm sido abordadas em diversos estudos no Brasil, como o de Pimenta (2010), e no exterior (LAMBERT; HOGAN; BARTON，2003; MCCABE; TREVIÑO; BUTTERFIELD，2001， MCCABE，2005; ANDERMAN; MURDOCK, 2011; MILLER et al., 2011; GARAVALIA et al., 2011; SIMHA; CULLEN, 2011; MARTIN, 2011), analisando variáveis diversas que consistem em elementos motivadores para comportamentos antiéticos.

Ainda que poucos estudantes admitam realizar alguma prática desonesta (LAMBERT; HOGAN; BARTON, 2003), pode-se observar evidências de sua ocorrência em diferentes níveis de formação, desde o ensino fundamental até o superior, variando em qualidade e em quantidade, segundo o nível dos estudantes e de seu desenvolvimento social e moral (ANDERMAN; MURDOCK, 2011, GARAVALIA et al., 2011).

Especificamente no ensino superior, Lambert, Hogan e Barton (2003) apontaram que um dos fatores que motiva estudantes a se comportarem de forma desonesta é o fato de quererem ser aceitos nos grupos dos quais desejam fazer parte, além do desejo de se formar e de conseguir melhores qualificações. Ademais, observaram também que a prática desonesta no ensino superior pode consistir apenas em uma extensão de um hábito já comum ao estudante, que o praticava deste antes de seu ingresso na faculdade.

Apesar de já se ter pensado que um dos motivadores para a ocorrência de tais condutas na academia possa ser contextual, Miller et al. (2011) acreditam que variáveis relacionais e de contexto pouco contribuem para a análise da situação. Esses autores sugerem optar por estudos que avaliem os relacionamentos entre variáveis contextuais, como as características acadêmicas e motivacionais.

Fatores pessoais enquanto motivadores de atitudes desonestas também têm sido objeto de análise de estudos. Características como a impulsividade, a disposição para se arriscar, a 
necessidade de receber atenção, o baixo senso de responsabilidade e a ausência de autocontrole apresentam relação direta com a ocorrência de práticas desonestas. Entretanto, tal relação não é contundente da forma como o é quando se analisa fatores situacionais como, por exemplo, tamanho da turma, conteúdo da disciplina e das provas e políticas institucionais (SIMHA; CULLEN, 2011).

Além das motivações que levam discentes a se comportar de maneira duvidosa em suas atividades acadêmicas do ensino superior, existem também elementos que podem atuar como facilitadores de sua ocorrência. Tais elementos merecem ser estudados, já que, uma vez identificados, pode-se trabalhá-los para minimizar a ocorrência de práticas desonestas deles decorrentes.

\subsection{ELEMENTOS FACILITADORES DA OCORRÊNCIA DE PRÁTICAS DESONESTAS}

Os comportamentos desonestos estão relacionados a fatores como trabalhos muito complexos para o nível dos estudantes, estudantes não comprometidos com sua aprendizagem, professores que não demonstram interesse ou não têm habilidade para apoiar os alunos no processo de ensino-aprendizagem e o maior foco em bons resultados em detrimento ao processo de aprendizagem propriamente dito (KOHN, 2011).

Orosz et al. (2015) relacionaram as características dos professores à possibilidade do estudante 'colar' em suas disciplinas e identificaram que o ânimo e a motivação do professor podem ser fatores que influenciam a ocorrência de práticas fraudulentas. Além disso, observaram também que a percepção do professor como um exemplo a ser seguido e como um bom orientador podem despertar no aluno um desestímulo a tais práticas e interesse em aproveitar melhor a aula. No entanto, os autores supracitados destacam que, apesar da motivação e entusiasmo do professor, esses fatores não são os únicos capazes de influenciar a diminuição de práticas desonestas.

É neste cenário que o papel do professor se mostra relevante para mitigar a ocorrência de tais práticas. $\mathrm{O}$ docente deve desenvolver atividades que estimulem o comprometimento dos alunos e devem também demonstrar interesse em apoiar os discentes no processo de aprendizagem.

No entanto, não só a influência do professor caracteriza possibilidades de diminuição da ocorrência de ações desonestas. Outros fatores, como por exemplo a infraestrutura e os recursos disponíveis nas instituições, consistem em elementos que podem favorecer ou desfavorecer a ocorrência desses comportamentos indesejados. Pimenta (2010) destaca que a 
'cola' durante as avaliações é favorecida por turmas mais numerosas, e representa um obstáculo para os professores evitarem tais práticas, pois muitas vezes não há estrutura e recursos suficientes para diminuir o tamanho das turmas.

Neste contexto, dadas as diversas motivações e elementos que favorecem a ocorrência de práticas desonestas por parte de discentes do ensino superior, evidencia-se necessário que o professor inclua, em suas atividades cotidianas, ações voltadas para a minimização da ocorrência de tais práticas.

\subsection{AÇÕES PARA MINIMIZAR A OCORRÊNCIA DE PRÁTICAS DESONESTAS}

Diante da existência destes comportamentos antiéticos (SHIKIDA, 2016; McCABE, 2005; OROSZ et al., 2015), os professores de IES se veem na obrigação de contemplar em suas atividades pedagógicas não só os conteúdos básicos necessários para o processo de aprendizagem, mas também métodos e técnicas que diminuam a possibilidade dos discentes se comportarem de forma duvidosa.

Nesta linha, McCabe e Pavela (2004) apresentam uma lista de princípios que contribuem para a diminuição da ocorrência de práticas desonestas na academia e que deveriam ser considerados tanto pelos professores quanto pelas instituições das quais fazem parte (quadro 2).

Quadro 2 Princípios da integridade acadêmica

\begin{tabular}{l|l}
\hline \multicolumn{1}{c|}{ Princípio } & \multicolumn{1}{c}{ Descrição e Atividades } \\
\hline $\begin{array}{l}\text { Reconhecer e afirmar a integridade } \\
\text { acadêmica como um valor institucional } \\
\text { fundamental }\end{array}$ & $\begin{array}{l}\text { Reconhecer os atos de fraude na sociedade, para avaliar as } \\
\text { consequências reais e extrair delas o papel de regra que } \\
\text { possuem. }\end{array}$ \\
\hline $\begin{array}{l}\text { Reforçar o compromisso com os } \\
\text { processos de aprendizagem na vida }\end{array}$ & $\begin{array}{l}\text { A paixão do professor pelo ensino e a aprendizagem deveriam } \\
\text { ser motivadores para os estudantes. O professor deve analisar } \\
\text { seu papel e seu desempenho, para que não seja uma razão para } \\
\text { os estudantes sentirem desinteresse. }\end{array}$ \\
\hline $\begin{array}{l}\text { Afirmar o papel do professor como um } \\
\text { orientador e mentor }\end{array}$ & $\begin{array}{l}\text { Quando o professor motiva e gera impacto nos estudantes, eles } \\
\text { têm melhor disposição para evitar as práticas desonestas. }\end{array}$ \\
\hline $\begin{array}{l}\text { Ajudar os estudantes a compreender o } \\
\text { valor da internet }\end{array}$ & $\begin{array}{l}\text { O professor pode orientar o discente no uso correto da internet } \\
\text { como ferramenta, a qual contém informações valiosas. } \\
\text { Entretanto, é necessário filtrar essas informações, pois nem tudo } \\
\text { é útil ou verdadeiro. }\end{array}$ \\
\hline $\begin{array}{l}\text { Estimular a responsabilidade dos } \\
\text { estudantes na integridade acadêmica }\end{array}$ & $\begin{array}{l}\text { Uma vez que os estudantes percebem que há respeito pelas } \\
\text { regras e códigos de ética, é possível promover a participação } \\
\text { dos estudantes como corresponsáveis do processo de } \\
\text { conscientização. }\end{array}$ \\
\hline & $\begin{array}{l}\text { Ao estabelecer as condições das disciplinas, é fundamental que } \\
\text { o docente crie adequadamente o ambiente e as experiências de } \\
\text { formação dos estudantes, conhecendo suas expectativas, e que } \\
\text { eles também estejam cientes das condições da disciplina sobre } \\
\text { as atividades e avaliações. }\end{array}$ \\
\hline
\end{tabular}




\begin{tabular}{l|l}
\hline \multicolumn{1}{c|}{ Princípio } & \multicolumn{1}{c}{ Descrição e Atividades } \\
\hline $\begin{array}{l}\text { Estabelecer formas justas e criativas de } \\
\text { avaliação }\end{array}$ & $\begin{array}{l}\text { As avaliações devem se constituir em oportunidades de } \\
\text { aprendizagem para o estudante. }\end{array}$ \\
\hline $\begin{array}{l}\text { Diminuir as oportunidades para a } \\
\text { ocorrência de fraude }\end{array}$ & $\begin{array}{l}\text { As regras devem ser claras, com padrões de avaliação justos e } \\
\text { definidos para que saibam as condições que devem cumprir e } \\
\text { assim tenham menores oportunidades de fraudar. }\end{array}$ \\
\hline Responder às práticas desonestas & $\begin{array}{l}\text { Para os estudantes respeitarem as regras e tomarem consciência, } \\
\text { é preciso que estejam cientes de que a fraude não será ignorada } \\
\text { quando ocorrer. }\end{array}$ \\
\hline $\begin{array}{l}\text { Ajudar na definição dos padrões de } \\
\text { integridade acadêmica nas Universidades }\end{array}$ & $\begin{array}{l}\text { A criação, aplicação e atualização dos códigos de ética e da } \\
\text { integridade acadêmica devem ser esforços institucionais, com a } \\
\text { participação ativa de estudantes, autoridades e professores. }\end{array}$ \\
\hline
\end{tabular}

Fonte: McCABE; PAVELA (2004)

As práticas apresentadas no quadro 2 visam contribuir para comportamentos éticos dos discentes durante sua formação. Observa-se ainda que, além de contribuir para a minimização da ocorrência de práticas desonestas através da imagem que passam aos alunos, os professores deve também instruí-los a utilizar as ferramentas e tecnologias disponíveis de forma ética e responsável, comunicando-lhes sobre as regras e padrões de avaliação, além de promover sua participação como corresponsáveis pelo processo de conscientização ética e responsável.

Ademais, Pimenta (2010) reforça a importância do professor em revisar as formas de avaliação e de formação, pois as vê como possíveis promotoras das práticas desonestas na academia. Da mesma forma, Stephens e Gehlbach (2011) e Ramos e Guerra (2017) retomam os fatores estruturais que podem influenciar os estudantes, recomendando a análise e revisão das formas e atividades utilizadas em sala de aula e das metas estabelecidas para o processo de aprendizagem.

Frente a estas condições, Simha e Cullen (2011) propõem três sugestões direcionadas à atuação dos professores: (i) a busca pela aprendizagem e pela construção do conhecimento deve ser o principal resultado almejado, prioritariamente às boas qualificações, (ii) deve-se punir os atos desonestos, a partir de castigos justos e (iii) deve-se buscar reduzir as oportunidades propícias para a realizações de ações e condutas desonestas dos estudantes. Este último item pode ser alcançado a partir da compreensão das motivações e das formas que os estudantes agem ao praticar fraudes no ensino superior.

Neste cenário, compreende-se a existência de pressão sobre as instituições e sobre os professores para deixarem de encarar tais práticas e condutas como 'ocorrências normais', e sim como algo que não diz respeito às práticas e condutas éticas. Frente a isso, nota-se que os educadores devem desenvolver meios e/ou mecanismos por meio dos quais seja possível punir e mitigar a possibilidade de tais ações, uma vez que preparar os estudantes para a realidade laboral na qual possivelmente se inserirão no futuro faz parte das tarefas dos 
docentes e IES, e é de fundamental importância para a construção e desenvolvimento de uma conduta ética.

Dessa forma, acredita-se que, se as políticas de avaliação e punição forem exercidas e de forma justa, o comportamento dos discentes do ensino superior pode ser orientado de forma a minimizar condutas ímprobas (SIMHA; CULLEN, 2011). Fazendo isto, acredita-se que o relacionamento professor-aluno também pode ser melhorado e o conhecimento pode ser construído em conjunto (KOHN, 2011).

Diante disto, percebe-se que o professor é um elemento fundamental no processo de ensino-aprendizagem e também na orientação das condutas dos alunos. Isso implica que desenvolva uma participação mais proativa na sala de aula, no intuito de possibilitar que os alunos percebam quais condutas devem fazer parte de sua vida, o que possibilita o fortalecer de seu relacionamento com os discentes.

\section{PROCEDIMENTOS METODOLÓGICOS}

O presente estudo possui abordagem qualitativa, uma vez que busca trabalhar apenas com a interpretação da realidade dos professores participantes e entender o fenômeno (ocorrência de práticas desonestas no ensino superior), sem a intenção de promover mudanças sobre os comportamentos dos objetos analisados (BAUER; GASKELL, 2002).

A pesquisa possui natureza descritiva, visto que não houve interferência dos pesquisadores sobre os fatos. Ainda, os pesquisadores apenas registraram, analisaram, classificaram e interpretaram os fatos evidenciados (RAUPP; BEUREN, 2003).

Como estratégia de pesquisa foi realizado o estudo de caso (YIN, 2015), a partir do qual analisou-se um fenômeno social complexo em profundidade, ou seja, as práticas desonestas realizadas por discentes do curso de Administração. Neste estudo foram analisados professores de duas universidades públicas, uma no estado de Minas Gerais e outra no Paraná, de forma a avaliar o fenômeno referente às práticas desonestas realizadas por discentes. As universidades foram selecionadas de forma não aleatória, intencional e de acordo com a facilidade de acesso (EISENHARDT, 1989).

Os dados foram coletados durante o período de 2017 a 2018, a partir de questionários contendo perguntas estruturadas, enviadas por formulário eletrônico e por email, a dezoito professores (professor A, B, ..., Q, R) do curso de Administração, sendo dez deles vinculados a universidade do Paraná e oito a de Minas Gerais.

$\mathrm{O}$ roteiro de entrevistas contemplou questões relacionadas à percepção dos professores 
sobre: (i) definição e situações em que ocorrem práticas desonestas, (ii) motivações e elementos impulsionadores das práticas desonestas, (iii) o que é feito para minimizar suas ocorrências, (iv) o que é feito para puni-las. Tais aspectos consistiram nas categorias de análise definidas a priori à coleta de dados.

Após coletados, os dados foram analisados a partir da análise de conteúdo (BARDIN, 2016). As categorias e elementos (códigos) de análise utilizados são apresentados no quadro 3.

Quadro 3 Categorias e elementos de análise

\begin{tabular}{|c|c|c|}
\hline Categoria & Códigos (elementos de análise) & Autores \\
\hline \multirow{3}{*}{$\begin{array}{c}\text { Definição e } \\
\text { situações em que } \\
\text { ocorrem práticas } \\
\text { desonestas }\end{array}$} & $\begin{array}{c}\text { Trabalhos copiados, práticas fraudulentas para aprovação em } \\
\text { disciplinas, desrespeito à integridade acadêmica }\end{array}$ & Shikida (2016) \\
\hline & $\begin{array}{l}\text { 'Sussurros' em provas, 'cola', falsidade ideológica, uso de } \\
\text { equipamentos e materiais sem autorização }\end{array}$ & $\begin{array}{c}\text { Orosz et al. } \\
(2015) ; \text { McCabe } \\
(2005)\end{array}$ \\
\hline & $\begin{array}{c}\text { Fazer trabalhos individuais em grupo, falsificação de dados, uso } \\
\text { inadequado da tecnologia }\end{array}$ & McCabe (2005) \\
\hline \multirow{5}{*}{$\begin{array}{c}\text { Motivações e } \\
\text { elementos } \\
\text { facilitadores da } \\
\text { ocorrência de } \\
\text { práticas desonestas }\end{array}$} & $\begin{array}{l}\text { Querer ser aceito em grupos, desejo de se formar e conseguir } \\
\text { melhores qualificações }\end{array}$ & $\begin{array}{l}\text { Lambert, Hogan e } \\
\text { Barton (2003) }\end{array}$ \\
\hline & $\begin{array}{c}\text { Características pessoais (impulsividade, disposição para se arriscar, } \\
\text { baixo senso de responsabilidade etc.) }\end{array}$ & $\begin{array}{l}\text { Simha e Cullen } \\
\qquad(2011)\end{array}$ \\
\hline & $\begin{array}{l}\text { Complexidade dos trabalhos, falta de comprometimento dos } \\
\text { estudantes }\end{array}$ & Kohn (2011) \\
\hline & Professores desinteressados e sem habilidade & $\begin{array}{l}\text { Kohn }(2011) \\
\text { Orosz et al. }(2015)\end{array}$ \\
\hline & Turmas numerosas & Pimenta (2010) \\
\hline \multirow{5}{*}{$\begin{array}{c}\text { Ações para } \\
\text { minimizar e punir } \\
\text { práticas desonestas }\end{array}$} & Revisar as formas de avaliação e de formação & $\begin{array}{l}\text { Pimenta (2010); } \\
\text { Stephens e } \\
\text { Gehlbach (2011); } \\
\text { Ramos e Guerra } \\
\text { (2017); McCabe e } \\
\text { Pavela (2004) } \\
\end{array}$ \\
\hline & Reduzir oportunidades propícias para práticas desonestas & $\begin{array}{c}\text { Simha e Cullen } \\
\text { (2011); McCabe e } \\
\text { Pavela (2004) }\end{array}$ \\
\hline & Buscar a aprendizagem, punir os atos desonestos & $\begin{array}{l}\text { Simha e Cullen } \\
(2011)\end{array}$ \\
\hline & Busca pelo conhecimento em conjunto & Kohn (2011) \\
\hline & $\begin{array}{c}\text { Reconhecer a integridade acadêmica, reforçar compromisso com } \\
\text { processos de aprendizagem, afirmar o papel do professor, ajudar } \\
\text { estudantes a compreender o valor da internet, estimular a } \\
\text { responsabilidade dos estudantes, esclarecer suas expectativas, } \\
\text { responder às práticas desonestas, ajudar a definir os padrões de } \\
\text { integridade acadêmica }\end{array}$ & $\begin{array}{l}\text { McCabe e Pavela } \\
\text { (2004) }\end{array}$ \\
\hline
\end{tabular}

Fonte: Elaborado pelos autores, a partir da base teórica (2018). 
A análise de conteúdo foi realizada seguindo as três etapas propostas por Bardin (2016), ou seja, (i) pré-análise, na qual foi feita uma leitura flutuante do material disponível na literatura, que trata do fenômeno aqui estudado, (ii) exploração do material, que permitiu a definição das categorias de análise, e, (iii) tratamento dos dados, que permitiu a realização de inferências acerca das evidências encontradas, bem como o estabelecimento da relação dos dados empíricos com a teoria.

\section{APRESENTAÇÃO E ANÁLISE DOS RESULTADOS}

\subsection{PRÁTICAS DESONESTAS E SITUAÇÕES EM QUE OCORREM}

Atitudes que podem comprometer o bem coletivo, como também burlar o sistema são consideradas práticas desonestas. Quando questionados sobre como definem as práticas desonestas, sete dos professores entrevistados apontaram que tal conceito está relacionado a atitudes orientadas para obtenção de vantagens pessoais, como pode ser observado nas falas de alguns deles.

Ação ou omissão que leve a vantagem pessoal ou profissional que tenha em sua origem ou decorrer restrição de direito de outrem (seja este outrem um indivíduo ou a sociedade como um todo) (Professor G).

Atitude de quem que se aproveita de outros para obter vantagens indevidas, prejudicando a coletividade (Professor I).

Uma prática desonesta é aquela em que se tenta driblar o sistema para favorecimento próprio (Professor J).

Essa definição vai ao encontro do conceito de antiética, que diz respeito à obtenção de vantagens pessoais em detrimento a um bem coletivo (NALINI, 2009). Assim, observa-se que a definição de práticas desonestas está intimamente relacionada com comportamentos antiéticos.

Exemplos desse tipo de práticas consistem, segundo McCabe (2005) e de Orosz et al. (2015), no ato de colar com ou sem o consentimento do outro e a realização de plágio ao copiar ou parafrasear textos impressos ou digitais sem as devidas citações, entregar trabalhos copiados de outros colegas, dentre outros. Esse código (plágio) teve incidência na fala de cinco professores entrevistados, dentre elas:

(...) A questão de copiar trabalhos, plagio, de livros de artigos, copia de isso, resumo copiado. (Professor A)

Por meio do uso de fontes sem a devida citação, seja da forma direta ou indireta, conforme algum padrão, ABNT, APA ou outro. (Professor E)

Basicamente, plágio. (Professor R) 
Doze participantes afirmaram que a cópia, sem suas devidas citações, bem como a cópia de trabalhos de outros colegas consistem nas principais situações desonestas identificadas. É possível observar nos excertos abaixo, algumas práticas desonestas identificadas pelos professores J e L.

[...] sugar resumos, trabalhos e explicações de outros estudantes para "se dar bem" na aula, fazer o mínimo esforço de leitura. pegar a ideia de outro sem lhe dar crédito [...]. (Professor J)

Alunos que copiam sem citar os autores, que não preparam as apresentações e usam as de colegas, que não leem os textos e tentam enrolar, cópia de trabalhos de colegas, que adulam professores para levar vantagens, entre outras. (Professor L)

Seis entrevistados apontaram a presença da prática da 'cola' e cinco entrevistados afirmaram já terem se deparado com trabalhos acadêmicos que continham o nome de alunos que não participaram efetivamente de sua realização.

Também constatado como definição de prática desonesta foi a não conformidade com as normas e quebra de regras ao afirmar que o desrespeito à integridade acadêmica da IES consiste numa prática desonesta (SHIKIDA, 2016). Concordando com o autor, a não conformidade com as normas foi outra definição identificada na fala de cinco entrevistados (professores A, B, C, $\mathrm{N}$ e O). As falas dos professores $\mathrm{B}$ e $\mathrm{C}$ exemplificam algumas dessas definições.

Qualquer atitude que burle regras pré estabelecidas. (Professor B)

Uma prática desonesta ou fraudulenta ocorre quando alguém desvia seu comportamento frente a regras, leis e ética. (Professor C)

Outras definições mencionadas por professores e que se mostram relacionadas à obtenção de vantagens pessoais em detrimento da coletividade foram: compra de trabalhos, 'cola', falsificação de dados e fingimento. Tais atitudes beneficiam o autor da prática, fazendo com que tenha que quebrar regras e padrões estabelecidos como éticos e corretos.

Também foram mencionadas nas falas dos entrevistados, ainda que com menor incidência, situações em que ocorreram outras práticas desonestas, como falsidade ideológica, alunos que usam trabalhos dos colegas, mentira de alunos para tentar conseguir vantagens como aumento do prazo para entrega de trabalhos e compra de trabalhos.

Tais situações vão ao encontro de Shikida (2016), que afirma que trabalhos copiados e práticas fraudulentas para obtenção de aprovação em disciplinas são situações de práticas desonestas, e também corroboram Orosz et al. (2015), que afirmam ser a falsidade ideológica uma situação evidenciada em estudos sobre desonestidade acadêmica e recorrente na 
academia. A partir dessas evidências, é possível observar que tais práticas vão além do plágio, consistindo em 'colas', fingimentos, cópias de trabalhos, dentre outros (SHIKIDA, 2016; OROSZ et al., 2015; McCABE, 2005).

Assim, é possível inferir que a concepção do conceito de práticas desonestas não pode ser restrita. Isso porque pode comprometer as ações que possam vir a tomar para diminuir essas práticas, uma vez que, por exemplo, ao considerar que consistam apenas no 'plágio', esses professores irão focar suas ações para minimizar essa ocorrência, e não das outras ações que também consistem em práticas desonestas.

\subsection{MOTIVAÇÕES E FACILITADORES PARA A REALIZAÇÃO DE PRÁTICAS DESONESTAS}

Diversas motivações para realizar práticas desonestas foram evidenciadas pelos professores do curso de Administração aqui pesquisados. Oito professores entrevistados apontaram a falta de punição como sendo um dos principais fatores motivadores para a ocorrência de tais práticas. Essa falta de punição corrobora ao afirmado por Simha e Cullen (2011) e McCabe e Pavela (2004) que acreditam que tal ato contribui para evitar a reincidência de práticas desonestas.

Outras motivações constatadas nas falas dos entrevistados foram a falta de esforço por parte do aluno (professores A, D, F, I, J), bem como o uso inadequado da internet (professores A, N, O, Q, R). A falta de esforço é convergente com os resultados apontados por Kohn (2011), que acredita que os estudantes não são comprometidos com sua aprendizagem, algo que consiste em um dos vários fatores que podem motivá-los a agir desonestamente.

O uso inadequado das tecnologias disponíveis, como a internet, por exemplo, foi evidenciado em cinco falas dos participantes entrevistados, corroborando McCabe e Pavela (2004).

Além destes elementos motivadores, a não valorização do curso e fatores culturais (presente em quatro excertos das entrevistas, cada um) também foram citados como influenciadores da ocorrência de práticas desonestas no ensino superior. A não valorização do curso condiz com o pensar que a universidade consiste apenas em um meio para adquirir um diploma, indo ao encontro de Simha e Cullen (2011). Isso é um exemplo de maior enfoque dado a bons resultados, em detrimento a um bom processo de aprendizagem, como apresentado por Kohn (2011).

Aspectos culturais relacionados à política e aos valores da sociedade na qual se inserem 
os alunos também podem ser evidenciados nas falas dos professores I e J.

É um problema cultural, pois muitos se acham no direito de cometer irregularidades em função do que acontece no meio político e também os que tentam burlar regras para alcançar objetivos sem esforço. (Professor I) Em minha opinião, é viver em uma sociedade que dá valor para a aparência e títulos e não para o conhecimento em si. (Professor J)

É possível observar na fala desses professores que os alunos são influenciados pelo contexto no qual estão inseridos, com objetivo de atender ao que é dado valor pela sociedade, ou seja, num contexto no qual corrupções e quebra de regras são comumente praticados.

Outra motivação para a realização de práticas desonestas identificada nas falas de dois participantes da pesquisa foi a importância dada para o desejo de se qualificar em detrimento à importância dada ao conhecimento, corroborando Lambert, Hogan e Barton (2003).

Também identificadas nas falas de dois participantes foram as características pessoais do aluno. Para o professor R, por exemplo, "a disposição pessoal para fraude" é um elemento que pode impulsionar a ocorrência de práticas desonestas por alunos do ensino superior. Essa evidência corrobora Simha e Cullen (2011) que afirmam que as características pessoais dos indivíduos podem contribuir para a ocorrência de comportamentos desonestos.

Com incidência em apenas um excerto das entrevistas, outros elementos que motivam a ocorrência de ações desonestas foram apontados, como: falta de confiança do aluno, facilidade de acesso a materiais, falta de conhecimento e atenção quanto às normas, dificuldade dos professores identificarem tais práticas, pressão e má gestão do tempo.

Os professores E e L apontaram o papel do docente como significativo para a ocorrência de práticas desonestas por parte dos discentes. Segundo o professor E, a "falta de planejamento do professor" pode contribuir para que o aluno pratique fraudes nos trabalhos e avaliações, pois "o aluno sabe quando o professor lê o trabalho e quando apenas o verifica". Para o professor L, "professores pouco comprometidos que não leem e não acompanham de perto os trabalhos dos alunos" propiciam a ocorrência de práticas desonestas por parte dos alunos. Tais resultados vão ao encontro do apontado por Pimenta (2010) e Ramos e Guerra (2017) que apontam as metodologias e formas de avaliação utilizadas pelos professores como fatores que contribuem para a promoção ou não de práticas desonestas por parte dos alunos.

\subsection{AÇÕES PARA DIMINUIR E PUNIR PRÁTICAS DESONESTAS NO ENSINO SUPERIOR}

Em relação às ações tomadas pelos professores para diminuir a ocorrência de fraudes, metade dos respondentes afirmou que a principal delas é a comunicação das normas e das 
consequências de se infringi-las. Tais ações vão ao encontro de McCabe e Pavela (2004) que apontam o esclarecimento das expectativas do docente para com o discente como sendo um dos princípios para minimizar a ocorrência de práticas desonestas. Os professores que apontaram tal ação afirmam desenvolvê-la de diversas formas:

Falar para os alunos sempre, lembrar sempre, reforçar, principalmente no começo das aulas, e sempre que vou falar de algum trabalho. (Professor A) Informo por escrito as regras das disciplinas que ministro. (Professor $\mathrm{C}$ ) (Colocar) Observação para provas. (Professor D)

Também constatada nas falas dos entrevistados, outra ação tomada pelos professores para diminuir práticas desonestas diz respeito à utilização de ferramentas para identificar o plágio (como a internet e softwares anti-plágio, por exemplo). Os professores D, E, J e N acreditam que, utilizando tais ferramentas, estão respondendo às práticas desonestas de alguma forma (McCABE; PAVELA, 2004). Ao fazerem isso, os professores acreditam que o aluno possa não se comportar desonestamente novamente.

A utilização de formas de avaliação que são menos propícias para a ocorrência de cola e plágio também foi mencionada por dois professores (professores G e J). Essas evidências vão ao encontro de Pimenta (2010) que afirma que as formas de avaliação e de formação devem ser revistas, de forma a reduzir as oportunidades dos estudantes em praticar ações fraudulentas.

Ainda que tenha se mostrado evidente na resposta de apenas três professores ( $\mathrm{J}, \mathrm{M} \mathrm{e} \mathrm{R}$ ), o princípio apontado por McCabe e Pavela (2004) referente a 'estimular a responsabilidade dos estudantes' é abordado por estes professores. O professor M faz discussões sobre o tema, em particular ou em grupo, estimulando a responsabilidade dos alunos na execução de práticas desonestas. Já os professores J e R também fazem isso, mas de forma diferente, como afirmam.

Peço uma declaração de que o trabalho foi passado por software anti-plágio e declaração do estudante atestando que o trabalho está livre de plágio. (Professor J)

(através da) conscientização dos alunos. (Professor R)

Observa-se que ações que visam estimular a responsabilidade do aluno contribuem para que as práticas desonestas sejam mitigadas, uma vez que trabalham a consciência ética do estudante. Conforme um dos princípios identificados por McCabe e Pavela (2004), pois quando estudantes percebem uma conduta desrespeitosa e contrária à ética, é possível integrálos e promover sua participação no processo de conscientização. 
Ainda que com menor incidência, o 'acompanhamento de perto' do aluno foi mencionado por três professores pesquisados. Esta ação corrobora um dos princípios de McCabe e Pavela (2004), uma vez que apontam que o professor deve reforçar seu compromisso com os processos de ensino-aprendizagem.

Ações que incidiram na fala de apenas um entrevistado foram: a conversa com os pares (professor E) e a verificação do comportamento e perfil do aluno para tentar identificar aqueles mais propensos a praticar ações fraudulentas (professor I).

A conversa com os pares (MILLER et al., 2011) está relacionada a um reforço do compromisso do professor com o processo de aprendizagem (McCABE; PAVELA, 2004) e contribui para a revisão de formas de avaliação e formação (PIMENTA, 2010; STEPHENS, GEHLBACH, 2011; RAMOS, GUERRA, 2017; McCABE, PAVELA, 2004), uma vez que, conversando com outros professores, o docente pode trazer para a sala de aula atividades e métodos diferentes dos que usa, minimizando a possibilidade de ocorrência de práticas fraudulentas.

O professor I apontou que busca identificar o perfil do aluno, entretanto tal ação vai de encontro a Miller et al. (2011), que constataram em seu estudo que não existe um perfil de aluno mais propenso do que outro a realizar ações desonestas. Assim, tal ação mostrar-se-ia ineficiente para mitigar a ocorrência de tais práticas.

Por outro lado, ainda que McCabe e Pavela (2014) recomendem a realização de ações voltadas para a autoavaliação dos professores, tais ações não foram evidenciadas nas falas dos participantes desta pesquisa.

A punição foi outra ação evidenciada na fala de dois professores (professor C e I) que acreditam que isso pode diminuir com o passar do tempo. Tais constatações vão ao encontro de McCabe e Pavela (2004) que afirmam ser necessário responder às práticas desonestas, e de Simha e Cullen (2011) que acreditam que a punição contribui para mitigar a ocorrência de tais práticas.

Como a punição de práticas desonestas é uma forma de evitar sua reincidência no futuro (SIMHA; CULLEN, 2011; McCABE; PAVELA, 2004), quando questionados sobre as ações que realizam para isso, oito dos professores entrevistados mencionaram que zeram o trabalho ou prova quando flagram uma prática desonesta.

Além disso, quatro deles (professores C, E, L e O) mencionaram que apenas descontam nota da atividade quando tal prática é identificada e outros quatro professores (professores B, G, J e N) mencionaram que já tiveram que recorrer a instâncias superiores, para pedir 
desligamento do aluno por plágio ou por identificação de um caso de falsidade ideológica.

Além dessas ações, o alerta aos alunos sobre o risco de sofrerem consequências mais severas em caso de plágio (professor A) e a explicação de como proceder em atividades acadêmicas futuras (professor F) auxiliam na aplicação do princípio apontado por McCabe e Pavela (2004) quanto a estimular a responsabilidade dos estudantes na integridade acadêmica. Ações como estas contribuem para demonstrar aos alunos que as regras devem ser cumpridas.

As constatações permitiram identificar o que são consideradas práticas desonestas na visão dos professores, as situações nas quais ocorrem, as ações tomadas pelos professores entrevistados para minimizar a ocorrência de tais práticas e as punições realizadas quando identificadas práticas desonestas por parte dos alunos.

\section{CONSIDERAÇÕES FINAIS}

Neste estudo foi possível notar que professores continuam enfrentando casos de estudantes que, por diversas razões, optam por seguirem 'o caminho fácil' e acabam se comportando de forma desonesta. Não raro, a realização de práticas desonestas é algo comum e frequente no ensino superior em Administração, principalmente porque observou-se que as ações para minimizá-las e puni-las mostram-se como parte do planejamento de aula dos professores, assim como são parte do trabalho no 'dia a dia' acadêmico. Evidencia-se no estudo que a indiferença frente à fraude tende a não fazer com que ela se torne menos frequente, o que tende a fazer com que tais comportamentos fraudulentos sejam reduzam está vinculado às práticas do professor, a forma como lida com os alunos e desempenha suas atividades.

Aliado a isso está o estabelecimento e o cumprimento de regras, além de uma conscientização dos indivíduos que estão em formação, ou seja, os alunos. Isso porque mostra-se mais importante fazer com que os estudantes tomem consciência das implicações que essas práticas trazem para sua vida acadêmica e profissional, utilizando o momento no qual o aluno realiza alguma fraude como o momento correto para ensinar.

Alunos mais conscientes acerca do que é correto e ético tendem a desenvolver um maior foco no processo de aprendizagem, na obtenção do conhecimento e reconhecem a importância da universidade como instituição facilitadora da obtenção deste conhecimento.

Sendo assim, é possível notar que o professor precisa conhecer e aprender as diversas técnicas usadas pelos estudantes para fraudar as avaliações, e principalmente estabelecer meios e/ou mecanismos para diminuir isso. Atividades de compartilhamento de experiências 
foram verificadas na fala de apenas um participante do estudo, o que sugere a necessidade de maior integração entre os pares para auxiliar na mitigação de tais práticas. Ou seja, por exemplo, com a existência de parceria e melhor comunicação entre seus pares, no intuito de fazer um intercâmbio de experiências e de conhecer os casos e práticas, passados e atuais, torna-se possível que consigam evitar sua ocorrência.

Mas não só, os dados empíricos desta pesquisa permitiram observar que o contexto no qual os alunos estão inseridos influencia suas ações, vez que alunos tendem a seguir o que e quem os influencia. Embora a literatura não mostre que o contexto é relevante para a realizacao de práticas desonestas, isso foi evidenciado nas falas dos professores aqui analisados.

Ainda que tenha cumprido com os objetivos propostos, o presente estudo apresentou limitações como (i) o número de professores entrevistados e o fato de que (ii) os professores entrevistados pertenciam apenas a universidades públicas. Tais limitações impossibilitam a generalização dos resultados encontrados.

Frente aos resultados obtidos com a pesquisa, constatou-se que há necessidade de se pesquisar outros temas para possibilitar um aprofundamento na análise das práticas desonestas. Sugere-se, como pesquisa futura, a exploração das experiências dos professores em criar ambientes idôneos para o aprendizado e, assim, entender se no Brasil o curso motiva o estudante a ser mais ou menos desonesto. Recomenda-se também a realização de análises comparativas entre universidades públicas e privadas sobre as práticas realizadas para reforçar a integridade acadêmica, algo que pode vir a retratar diferentes formas de atuação quanto a conduta referente a tais práticas.

Diante desses aspectos, espera-se que o presente trabalho tenha contribuído para a literatura sobre o tema com dados empíricos que permitam maior compreensão da ocorrência de práticas desonestas, bem como para que IES e professores do ensino superior em Administração consigam contemplar em suas ações práticas a fim de evitar a ocorrência de comportamentos desonestos dos estudantes. Espera-se também que esta pesquisa tenha contribuído para elucidar aos docentes do ensino da Administração acerca de sua prática pedagógica, principalmente com relação à realização de ações voltadas para a prevenção da ocorrência de práticas desonestas em detrimento a ações meramente reativas na conscientização e formação dos alunos. 


\section{REFERÊNCIAS}

AKTOUF, O. Ensino em administração: por uma pedagogia para a mudança. Organizações \& Sociedade, Salvador, v. 12, n. 35, p.151-159, 2005.

ALCADIPANI, R. Academia e a Fábrica de Sardinhas. Organizações \& Sociedade, Salvador, v. 18, n. 57, p.346-348, 2011.

ANDERMAN, E.; MURDOCK, T. (Eds.). Psychology of Academic Cheating. Estados Unidos: Elsevier Academic Press, 2011.

ANDRADE, M. Como preparar trabalhos para cursos de pós-graduação: noções práticas. 4ed. São Paulo: Atlas, 2001.

BARDIN, L. Análise de conteúdo. São Paulo: Edições 70, 2016.

BAUER, M. W.; GASKELL, G. Pesquisa qualitativa com texto, imagem e som: um manual prático. Petrópolis: Vozes, 2002.

BORGES, J. F.; MEDEIROS, C. R. O.; CASADO, T. Práticas de gestão e representações sociais do administrador: algum problema? Cadernos EBAPE. Rio de Janeiro, v. 9, edição especial, p. 530-568, 2011.

CRUZ, B. "Causos" de um professor de administração na hipermodernidade. In: ENEPQ, 2, 2009, Curitiba: Anpad, 2009.

EASTMAN, K. J.; IVER, R.; REISENWITZ, T. H. The Impact of Unethical Reasoning On Different Types of Academic Dishonesty: An Exploratory Study. Journal of College Teaching \& Learning. Estados Unidos, v. 5, n. 12, p. 7-16, 2008.

EISENHARDT, K. M. Building Theories from Case Study Research. Academy of Management Review, v.14, n.4, p.532-550, 1989.

FREITAS, M. A carne e os ossos do ofício acadêmico. Organizações \& Sociedade, Salvador, v. 14, n. 42, p.187-191, 2007.

FROTA, G.; TEODÓSIO, A. Profissão Docente, Profissão Decente?: Estratégias de Professores Frente ao Sofrimento no Trabalho em um Ambiente de Inovação Pedagógica. In: ENANPAD, 2012, Rio de Janeiro. Anais... Rio de Janeiro: Anpad, 2012.

GARAVALIA, L.; OLSON, E.; RUSSEL, E.; CHRISTENSEN, L. How do students cheat? In: ANDERMAN, E. M.; MURDOCK, T. B. Psychology of Academic Cheating. Estados Unidos: Elsevier Academic Press, 2011.

KOHN, A. Foreword. Psychology of Academic Cheating. Anderman, E. e Murdock, T. (Eds). Estados Unidos: Elsevier Academic Press, 2011.

LAMBERT, E.; HOGAN, N.; BARTON, S. Collegiate Academic Dishonesty Revisited: What have they done, how often have they done it, who does it, and whay did they do it? 
Electronic Journal of Sociology, 2003.

MARTIN, D. Undestanding Plagiarism Behavior through Criterion Studies: Predictors of Actual Plagiarism. Handbook of Research on Teaching Ethics in Business and Management Education. Wankel, C. e Stachowicz-Stanusch, A. (Eds.) Estados Unidos: IGI Global, 2011.

MATOS, R. S.; SOUZA, I. M.; SILVA, F. M.; BECK, G. G. L. Gestão do Planejamento e Acompanhamento de Atividades Docentes de uma Universidade Federal. Gestão Universitária na América Latina - GUAL, v. 12, n. 1, 2019.

MCCABE, D. Cheating among college and university students: A North American perspective International Journal for Educational Integrity, v.1, n.1, 2005.

MCCABE, D.; PAVELA, G. Ten (updated) principles of academic integrity. Change. 2004.

MCCABE, D.; TREVIÑO, L.; BUTTERFIELD, K. Cheating in Academic Institutions: A Decade of Research. Ethics \& Behavior, v.11, n.3, 2001.

MILLER, A. D.; MURDOCK, T. B.; ANDERMAN, E. M.; POINDEXTER, A. L. Who are all these cheaters? Characteristics of academically dishonest students. Psychology of Academic Cheating. Anderman, E. e Murdock, T. (Eds.). Estados Unidos: Elsevier, 2011.

NALINI, J. R. Ética geral e profissional. 7.ed. São Paulo: Editora Revista dos Tribunais, 2009.

OROSZ, G.; TÓTH-KIRÁLY, I.; BÖTHE, B.; KUSZTOR, A.; ÜLLEI-KOVÁCS, Z.; JÁNVÁRI, M. Teacher enthusiasm: a potential cure of academic cheating. Frontiers in Psychology. v. 6, p. 1-12, 2005.

PIMENTA, M. A. A. Fraude em avaliações na visão dos professores e estudantes: uma reflexão sobre formação professional e ética. RPD - Revista profissão docente, v.10, n.22, p.124-138, 2010.

RAMOS, F. S.; GUERRA, M. G. G. V. Oficinas de educação para a ética e introdução à metodologia científica como instrumento de desestímulo ao plágio. Revista Tempo e Espaços em Educação, v.10, n.23, 2017.

RAUPP, F. M.; BEUREN, I. M. Metodologia da pesquisa aplicável às ciências sociais, In. M. Beuren (Ed). Como elaborar trabalhos monográficos em contabilidade: teoria e prática. São Paulo: Atlas, 2003.

SHIKIDA, C. Honestidade Acadêmica e Plágio: Observações Importantes, Working paper. Universidade Federal de Pelotas, Departamento de Eonomia, 2016. Disponível em: https://wp.ufpel.edu.br/economia/files/2016/06/cadernos_economicos_08.pdf. Acesso em: $26 / 12 / 2017$.

SILVA JUNIOR, A.; CORRÊA, V.; VASCONCELOS, P. O. M.; MONTEIRO, J. M. R. Dilemas éticos na perspectiva de discentes de graduação em Administração de uma 
Universidade Pública: A ambiguidade moral em cena. In: XX Semead, São Paulo. Anais..., 2017.

SIMHA, A.; CULLEN, J. Academic Dishonesty and Cheating: Proactive and Reactive Action Implications for Faculty and Students. Handbook of Research on Teaching Ethics in Business and Management Education. Wankel, C. e Stachowicz-Stanusch, A. (Eds.) Estados Unidos: IGI Global, 2011.

SOUSA, R. N.; CONTI, V. K.; SALLES, A. A.; MUSSEL, I. C. R. Desonestidade acadêmica; reflexos na formação ética dos profissionais da saúde. Rev.Bioét. v.24, n.3, 2016.

STEPHENS, J.; GEHLBACH, H. Under pressure and Under-engaged: motivational profiles and academic cheating in high school. Psychology of Academic Cheating. Anderman, E. e Murdock, T. (Eds.). Estados Unidos: Elsevier Academic Press, p.107-134, 2011

YIN, R. K. Estudo de caso: planejamento e métodos, 5.ed. Porto Alegre: Bookman, 2015.

ZAHRA, S. A.; PRIEM, R. L.; RASHEED, A. A. The Antecedents and Consequences of Top Management Fraud. Journal of Management. Estados Unidos, Sage Publications, v. 31, p. 803-828, 2005. 